\title{
Indoor Culturable Fungal Load and Associated Factors among Public Primary School Classrooms in Gondar City, Northwest Ethiopia, 2018: A Cross-sectional Study
}

\author{
Zewudu Andualem $^{1 *}$, Zemichael Gizaw ${ }^{1}$, Henok Dagne ${ }^{1}$
}

\footnotetext{
OPEN ACCESS

Citation: Zewudu Andualem, Zemichael Gizaw, Henok Dagne. Indoor Culturable Fungal Load and Associated Factors among Public Primary School Classrooms in Gondar City, Northwest Ethiopia, 2018: A Cross-sectional Study. Ethiop J Health Sci.2019; 29(5):623.

doi:http://dx.doi.org/10.4314/ejhs.v29

i5.13

Received: April 1, 2019

Accepted: June 9, 2019

Published: September 1, 2019

Copyright: (C2019 Zewudu Andualem, et al. This is an open-access article distributed under the terms of the Creative Commons Attribution License, which permits unrestricted use, distribution, and reproduction in any medium, provided the original author and source are credited.

Funding: Nil

Competing Interests: The authors declare that this manuscript was approved by all authors in its form and that no competing interest exists.

Affiliation and Correspondence:

${ }^{1}$ Department of Environmental and Occupational Health and Safety, Institute of Public Health, College of Medicine and Health Sciences, University of Gondar, Gondar, Ethiopia

*Email:

zewuduandualem12@gmail.com
}

ABSTRACT

BACKGROUND: Fungi are heavy threats to public health in indoor environments, particularly in residential buildings, offices, and schools where people spend a lot of time indoors. This study was conducted to investigate the load of culturable fungi and associated factors in a school indoor environment.

METHODS: Institutional based cross-sectional study was conducted in eight public primary school classrooms in Gondar City from March to April 2018. Settle plate technique was used to determine the culturable fungal load. Log transformed linear regression analysis was employed. The beta-coefficient with a 95\% confidence interval was used to determine the degree and direction of the association with a p-value less than 0.05 .

RESULTS: The highest and the lowest mean culturable fungal loads recorded were $1140.29 \mathrm{CFU} / \mathrm{m}^{3}$ and $211.25 \mathrm{CFU} / \mathrm{m}^{3}$, respectively. Aspergillus, Mucor, Penicillium, Candida, Microsporum, Trichophyton, Rhizopus, Alternaria and Fusarium species were isolated. Age of buildings $(\beta=-0.122,95 \% C I-0.238$,0.007), area of classroom $(\beta=0.639,95 \%$ CI 0.285, 0.993), temperature $(\beta=-0.189,95 \%$ CI $-0.325,-0.047)$, humidity $(\beta=-$ $0.023,95 \% C I-0.043,-0.002)$ and PM10 ( $\beta=-0.01,95 \% C I-0.015$,$0.005)$ were associated with culturable fungal load.

CONCLUSIONS: High culturable fungal load was found in school classrooms in Gondar City. Age of buildings, area of classrooms, temperature, humidity, and PM10 were predictors of the culturable fungal load. Therefore, proficient corrective methods are needed to combat the problem of indoor air quality in a school indoor environment by controlling factors contributing to growth of fungi. KEYWORDS: School indoor air, culturable fungal load, settles plate technique, Gondar City

\section{INTRODUCTION}

Indoor air quality is a foremost important factor affecting the health and well-being of people who inhale a minimum of $10-14 \mathrm{~m}^{3}$ of the air daily and spend between $80-95 \%$ of their lives indoors $(1,2)$. The air inhaled by individuals is profusely inhabited with microorganisms called bioaerosols(3). Bioaerosols are colloids, shaped by liquid 
droplets and particles of solid matter within the air, whose elements contain viruses, fungal spores, and conidia, plant pollen and fragments of plant tissues $(3,4)$.

Indoor air contamination is a health hazard as people spend much time in homes, offices and densely populated areas like schools (5). In 2016, WHO reported that globally, 3.8 million deaths were attributed to indoor air pollution. More than $90 \%$ of air pollution-related deaths occur in lowand middle-income countries, mainly in Asia and Africa, followed by low and middle-income countries of the Eastern Mediterranean region, Europe and Americas (5).

Fungi are present everywhere and are a significant threat to public health in indoor environments $(6,7)$. They are able to grow on most natural and synthetic materials, particularly absorptive or wet and inorganic materials get settled as they absorb dirt and function sensible growth substrates for Aspergillus fumigatus and Aspergillus versicolor (7). Fungal species like Cladosporium and Penicillium (Penicillium brevicompactum and Penicillium expansum) infest building materials and highly attack wood (8).

Biotic pollutants of the indoor air include fungi, bacteria, viruses, pollen, etc. Fungi are able to grow wherever there are moisture and organic substrates. Building materials like ceiling tiles, wood, paint, carpet rugs, etc., are a very good setting for the growth of fungi (9). Potential sources of biotic pollutants of indoor air comprise people, organic dust, various materials stored in buildings, and also the air influent from the ventilation and air conditioning systems (10).

About $2-6 \%$ of the overall population in developed countries is allergic to fungi, and the higher susceptibility is distinguished concerning genera of Alternaria, Cladosporium, Aspergillus, Penicillium and Fusarium (11). Exposure to fungi has been reported to cause several types of human health problems, primarily irritations, infections, allergies and toxic effects, and it has been suggested that toxigenic fungi are the cause of additional adverse health effects (12). Adverse health effects are supposed to be linked with microbial growth in indoor areas and is mostly related with mold growth. Allergies are a predominant condition to be mentioned, followed by toxic alveolitis and reactions like (allergic) bronchitis, chronic obstructive pulmonary disease, and aggravation of asthma. Mold and bacterial infections are very rare, but people with immunodeficiency are particularly prone to fungal infections (13). It has been found that spores of fungi contain fungal toxins (mycotoxins), which are well known from food contaminations (13). However, their load and contributing factors in the school indoor environment is not well investigated in Ethiopia. This study was, therefore, conducted to assess the indoor culturable fungal load and its associated factors among school classrooms in Gondar City, Northwest Ethiopia.

\section{MATERIALS AND METHODS}

Study design and study area: Institutional based cross-sectional study was conducted to assess indoor culturable fungal load and its associated factors in public primary school classrooms in Gondar City, Northwest Ethiopia. The details of the method (study setting, sample size determination, and sampling technique) are presented well elsewhere (14).

Assessment of the physical characteristics of classrooms: Structured checklist was used to assess factors associated with the indoor culturable fungal load, such as the age of buildings, condition of the buildings, construction status, window safety conditions, cross-ventilation, area of classroom $\left(\mathrm{m}^{2}\right)$, classroom cleaning frequency, and a number of windows. Physical parameters like PM2.5, PM10, temperature, humidity and carbon dioxide concentration in the classrooms were measured by using Airveda.

Aireveda is an instrument used to measures PM2.5, PM10, $\mathrm{CO}_{2}$, temperature and humidity. It monitors use of high quality laser sensors, calibrated individually for Indian conditions against BAM (Beta Attenuation Monitor- the most advanced system for measuring ambient air quality). This device contains a high quality NDIR $\mathrm{CO}_{2}$ sensor, which allows the user to easily self-calibrate, ensuring the best results. Temperature and humidity sensors are calibrated by a master source traceable to NABL (15).

Air sampling procedures: Air samples were taken from fifty-one randomly selected classrooms of eight public primary schools in Gondar city. Passive air sampling method i.e., the settle plate method was used. Standard Petri dishes with $9 \mathrm{~cm}$ diameter $\left(63.585 \mathrm{~cm}^{2}\right.$ areas) containing culture media were

DOI: http://dx.doi.org/10.4314/ejhs.v29i5.13 
exposed. Fungalload was determined was based on the count of the microbial falls out on to Petri dishes left open to the air according to the $1 / 1 / 1$ scheme (for 1 hour, $1 \mathrm{~m}$ from the floor, at least 1 meter away from walls or any obstacle) $(16,17)$.

Fungi were collected on Sabouraud dextrose agar (SDA) media to which an antibacterial agent (Chloramphenicol) has been added to inhibit the growth of bacteria. Sampling was done in the morning (at 6:30 am, before students entered the classroom) and afternoon (5:00 pm, after students left the classroom) to determine the fungal concentration with respect to environmental variation. After exposure, the samples were taken to the laboratory (Department of Biology, at the University of Gondar) and incubated at $25{ }^{\circ} \mathrm{C}$ for 3 to 5 days. Sterile gloves, mouth masks, and protective gown were worn to avoid contamination of agar plates during air sampling and analysis. Openings like doors and windows were closed to minimize dilution of air contaminants $(3,18,19)$. Moreover, the movement of individuals throughout sampling was restricted to avoid air disturbance and lately emitted microorganisms. The agar plates were also checked visually before use for any microbial growth. Colony Forming Units (CFU) were enumerated and the load was determined using the following equation(20).

$$
\mathrm{N}=5 \mathrm{a} * 10000 / \mathrm{bt}
$$

Where: $\mathrm{N}=$ microbial $\mathrm{CFU} / \mathrm{m}^{3}$ of indoor air; $\mathrm{a}=$ number of colonies per Petri dish; $b=$ dish surface area $\left(\mathrm{cm}^{2}\right) ; \mathrm{t}=$ exposure time (minute).

Fungal isolation was identified on the basis of microscopic (using Lactophenol cotton blue staining) and macroscopic characteristics (with the aid of an Atlas of Mycology) (21, 22).

Data analysis: Statistical analysis was carried out with Kruskal-Wallis $\mathrm{H}$ test using Stata/SE software version 14.0 to know the mean fungal load difference between public primary schools. Log transformed linear regression was used to determine the relationship between mean fungal loads with independent variables. Statistically significant variables were identified on the basis of the beta coefficient with 95\% confidence interval and a pvalue less than 0.05 .

\section{RESULTS}

Socio-demographic characteristics: A total of 2722 students were attending classes in fifty-one randomly selected classrooms in eight public primary schools. A quarter $(25.49 \%)$ and threefourths $(74.51 \%)$ of the students were aged 5-11 and 12-19 years, respectively. The mean number of students per classroom was $53.37 \pm(\mathrm{SD}=$ 14.37).

Building and environmental sanitation information: From a total of 51 classrooms, $19(37.25 \%)$ classrooms were constructed from mud and wood, and 32(62.75\%) from bricks (Table 1).

Table 1: The building, sanitation and environmental related information of public primary school classrooms in Gondar city, Northwest Ethiopia, 2018.

\begin{tabular}{cll}
\hline Variables & Frequency & $\%$ \\
\hline Age of buildings & & \\
$\geq 18$ yr. & 19 & 37.25 \\
$<18$ yr. & 32 & 62.75 \\
Number of windows & & \\
Low & 1 & 1.96 \\
Average & 7 & 13.73 \\
High & 43 & 84.31 \\
Yes & & \\
No & 44 & 86.27 \\
Allows cross ventilation & 7 & 13.73 \\
Area of classroom & & \\
30- 64 m ${ }^{2}$ & 32 & 62.75 \\
$\geq 64$ m $^{2}$ & 19 & 37.25 \\
Cleaning frequency of classroom & & \\
Once a week & 35 & 68.63 \\
Two times a week & 16 & 31.37 \\
Condition of the buildings & & \\
Low & 35 & 68.63 \\
Average & 13 & 25.49 \\
High & 3 & 5.88 \\
Low & 13 & 25.5 \\
Construction status & 29 & 56.49 \\
High & 9 & 17.86 \\
High & & \\
Low & 27 & 52.94 \\
Average & 20 & 39.22 \\
High & 4 & 7.84 \\
\hline Window safety condition & &
\end{tabular}


Culturable fungal load in the school indoor environment: The lowest and the highest mean fungal loads were recorded at school 6 and school
2 as $211.25 \mathrm{CFU} / \mathrm{m}^{3}$ and $1140.29 \mathrm{CFU} / \mathrm{m}^{3}$, respectively. The total mean fungal load was 613.29 CFU $/ \mathrm{m}^{3}$ (Table 2).

Table 2: Statistical summary of mean fungal load in eight public primary school classrooms in Gondar city, Northwest, Ethiopia 2018

\begin{tabular}{lrrrrrr}
\hline $\begin{array}{r}\text { Name of } \\
\text { School }\end{array}$ & $\begin{array}{r}\text { Number of } \\
\text { Classrooms }\end{array}$ & Mean fungal load & $\begin{array}{r}\text { Standard } \\
\text { deviation }\end{array}$ & Median & Minimum & Maximum \\
\hline School 1 & 5 & 669.5 & 70.608 & 676 & 598 & 767 \\
School 2 & 7 & 1140.29 & 530.708 & 1157 & 591.5 & 2164.5 \\
School 3 & 3 & 613.17 & 30.719 & 624 & 578.5 & 637 \\
School 4 & 8 & 468.81 & 61.707 & 471.25 & 364 & 546 \\
School 5 & 7 & 382.57 & 72.617 & 377 & 253.5 & 494 \\
School 6 & 8 & 211.25 & 67.906 & 214.5 & 136.5 & 299 \\
School 7 & 7 & 1104.07 & 182.480 & 1118 & 916.5 & 1417 \\
School 8 & 6 & 377 & 80.977 & 396.5 & 273 & 455 \\
Total & 51 & 613.29 & 396.195 & 487.5 & 136.5 & 2164.5 \\
\hline
\end{tabular}

Fungal species were identified from the culture, and the result showed that Trichophyton species were found in all public primary schools while Aspergillus species were found in seven of the eight schools (Table 3). According to the sanitary standards for non-industrial premises, the degree of air pollution by fungal population across the various classrooms ranges largely between intermediate to high (Table 4).

Table 3: Type of microorganism isolated from each public Primary school classrooms in Gondar city, Northwest Ethiopia, 2018

\begin{tabular}{ccccccccccc}
\hline & \multicolumn{10}{c}{ Isolated Fungi } \\
\cline { 2 - 9 } Name of School & AS & MU & PE & CA & TR & RH & MS & AL & FU \\
\hline School 1 & + & - & + & + & + & - & - & - & - \\
School 2 & + & + & + & + & + & + & - & + & + \\
School 3 & + & + & + & + & + & - & - & - & + \\
School 4 & + & + & + & - & + & - & + & + & + \\
School 5 & + & - & - & + & + & - & - & + & - \\
School 6 & + & - & - & + & + & + & + & + & + \\
School 7 & - & - & - & - & + & - & - & + & + \\
School 8 & + & - & - & - & + & + & + & + & + \\
\hline
\end{tabular}

KEYS: $+=$ Present, $-=$ absent. AS $=$ Aspergillus species, $\mathrm{MU}=$ Mucor species, $\mathrm{PE}=$ Penicillium species, $\mathrm{CA}=$ Candida species, $\mathrm{MS}=$ Microsporium species, $\mathrm{TR}=$ Trichophyton species, $\mathrm{RH}=$ Rhizopus species, $\mathrm{AL}=$ Alternaria species, $\mathrm{FU}=$ Fusarium species

Kruskal-Wallis $\mathrm{H}$ test was conducted to obtain the mean fungal load difference among public primary schools as presented below. The highest mean fungal load, $1140.28 \mathrm{CFU} / \mathrm{m}^{3}$, in school 2 and the lowest, $211.25 \mathrm{CFU} / \mathrm{m}^{3}$, concentration in school 6 was recorded. The grand total mean fungal load was $613.29 \mathrm{CFU} / \mathrm{m}^{3}$. The Kruskal-Wallis $\mathrm{H}$ test showed that there was a significant mean fungal load difference in public primary schools $\left(\mathrm{X}^{2}=\right.$ $44.82, \mathrm{df}=7$ and $\mathrm{p}=0.0001$ ). 
Table 4: Assessment of indoor culturable fungal load according to the sanitary standards for non- industrial premises in public Primary school classrooms Northwest Ethiopia, 2018

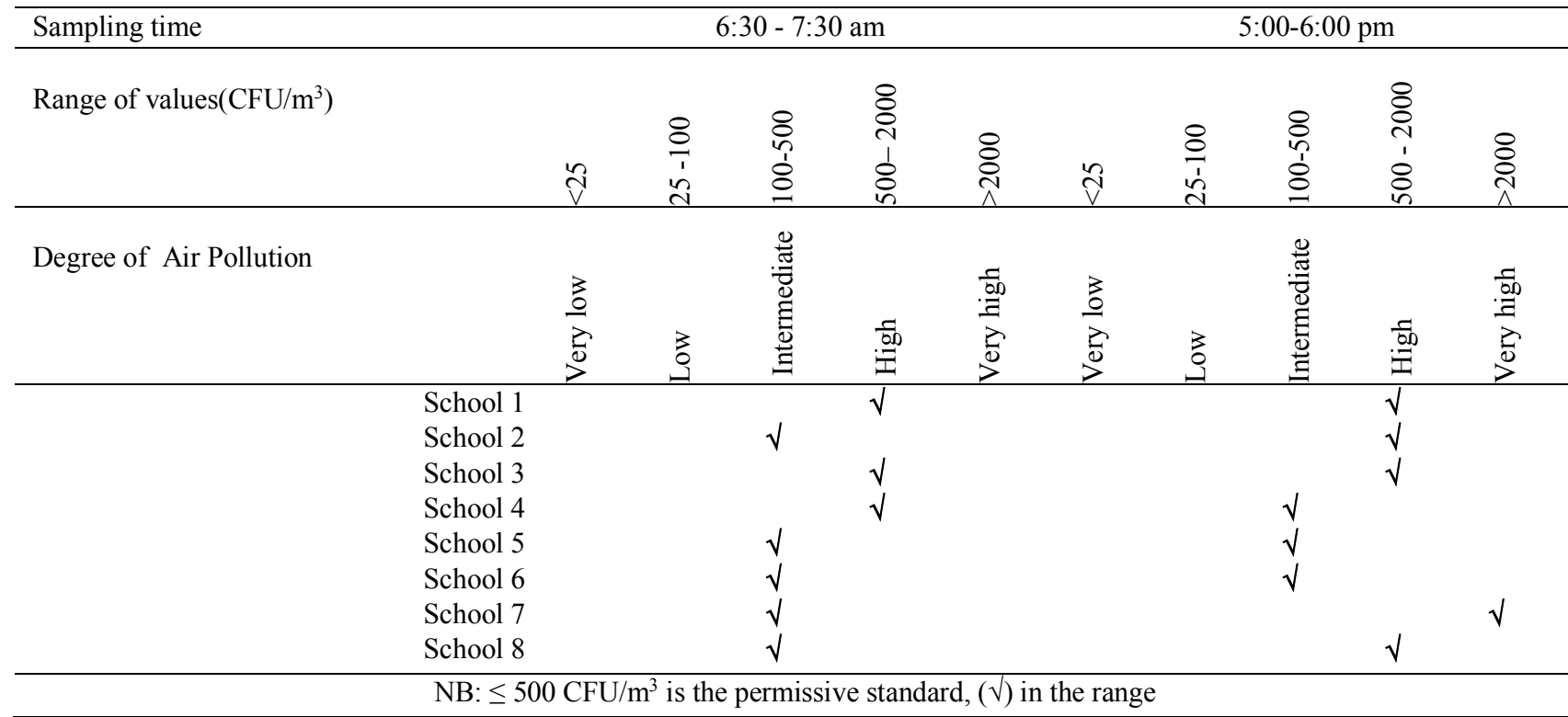

Factors associated with the mean indoor culturable fungal load: The results of the current study showed that the mean fungal load was significantly associated with age of buildings, indoor temperature, indoor humidity, PM10 and area of classroom (Table 5).

New age buildings had $12.2 \%$ lower fungal load than old age buildings $(\beta=-0.122,95 \% \mathrm{CI}$ $0.238,-0.007)$. Classrooms with small areas had $63.9 \%$ higher fungal load than Classrooms with large areas $(\beta=0.639,95 \%$ CI $0.285,0.993)$. With one unit increase in the indoor temperature, the mean fungal load declines by 0.186 units $(\beta=-$ $0.186,95 \%$ CI-0.325, -0.047). With one unit increase in the indoor humidity, the mean fungal load declines by 0.023 units $(\beta=-0.023,95 \%$ CI $0.043,-0.002)$. A $100 \%$ increase in the PM10 concentration will reduce the mean fungal load by $1 \%(\beta=-0.01,95 \%$ CI $-0.015,-0.005)$.

Table 5: Factors associated with the mean fungal load in public primary school classrooms in Gondar city, Northwest Ethiopia, 2018

\begin{tabular}{|c|c|c|c|c|c|}
\hline \multirow[t]{2}{*}{ Variables } & \multirow[t]{2}{*}{$\beta$ Coefficient } & \multirow[t]{2}{*}{ Std. Err } & \multirow[t]{2}{*}{$P$ - value } & \multicolumn{2}{|c|}{$[95 \% \mathrm{CI}$ for $\beta]$} \\
\hline & & & & $\mathrm{L}$ & $\mathrm{U}$ \\
\hline Age of buildings & -.122 & .059 & $0.038 *$ & -.238 & -.007 \\
\hline Area of classroom & .639 & .181 & $0.000 * *$ & .285 & .993 \\
\hline Mean $\mathrm{CO}_{2}$ & -.0002 & .005 & 0.962 & -.009 & .009 \\
\hline Mean $\mathrm{T}^{\circ} \mathrm{C}$ & -.186 & .071 & $0.008 *$ & -.325 & -.047 \\
\hline Mean humidity & -.023 & .011 & $0.033 *$ & -.043 & -.002 \\
\hline No of windows & .477 & .564 & 0.398 & -.629 & 1.583 \\
\hline Allow cross ventilation & -.395 & .858 & 0.645 & -2.07 & 1.287 \\
\hline Mean PM10 & -.010 & .003 & $0.000 * *$ & -.015 & -.005 \\
\hline Cleaning frequency of classroom & .168 & .173 & 0.332 & -.171 & .507 \\
\hline Safety Condition of windows & -.133 & .113 & 0.238 & -.354 & .088 \\
\hline Wall construction & -.129 & .238 & 0.586 & -.595 & .336 \\
\hline _cons & 9.753 & 2.09 & 0.000 & 5.656 & 13.85 \\
\hline$*=$ Significant associatic & $* *=p<0.001$ & $*=\mathrm{p}<0.0$ & & & \\
\hline
\end{tabular}

DOI: http://dx.doi.org/10.4314/ejhs.v28i1.2 


\section{DISCUSSION}

The fungal load ranged from 52-3900 $\mathrm{CFU} / \mathrm{m}^{3}$ with the total mean fungal load being 613.29 $\mathrm{CFU} / \mathrm{m}^{3}$ in school classrooms of Gondar City. The result of this study was lower than the result of a study conducted in Portugal $\left(1164 \mathrm{CFU} / \mathrm{m}^{3}\right)(23)$. On the contrary, the mean fungal load recorded in this study was found to be higher than the report of a study in Malaysia (292 CFU/m3) (24). The variation of mean fungal load indoor environments might be due to environmental factors such as building condition, window safety condition, and construction status, the ventilation system of the classroom, temperature, humidity, and particulate matter concentration.

Nine fungal species were isolated which included Aspergillus, Mucor, Penicillium, Candida, Microsporum, Trichophyton, Rhizopus, Alternaria and Fusarium species. The distribution of isolated fungal species in this study agreed with the works of Hussin N. et'al, (24) and Naruka K. et'al, (25).

The study conducted by a WHO expert group on the assessment of health risks of biological agents in indoor environments recommended that total microbial concentration should not exceed $1000 \mathrm{CFU} / \mathrm{m}^{3}(26)$. In healthy buildings, $\leq 750 \mathrm{CFU} / \mathrm{m}^{3}$ was the limit for fungi where species were not infectious (27). According to the sanitary standards of the European Commission for non-industrial premises, the permissible limits of fungal load was $\leq 500$ $\mathrm{CFU} / \mathrm{m}^{3}(28)$. Due to the absence of generally accepted threshold limit values regarding concentrations of the air of indoor fungi, the obtained results could be compared solely with the values suggested by various authors or institutions.

In this study, age of the building had a significant association with the airborne fungal load. This is in agreement with studies conducted in Iraq (29), India (25), and Nigeria (19). The possible explanation might be the fact that buildings with new-age contain low moisture content than old age buildings that can affect fungal load. Indoor fungal contamination during major demolition-construction work might help to detect increased fungal loads (30). Area of the classroom was significantly associated with fungal load. The possible explanation might be the fact that a large area of the classroom allows better ventilation thereby reducing the fungal load (31).

In this study, temperature was negatively associated with the airborne fungal load. This finding agrees with a study conducted in India (25). The significant association between temperature with indoor airborne fungal load was not consistent with what is expected since a positive correlation between fungal load and temperature was already reported (32). The possible explanation for the negative association might be the effects of temperature on settling velocity of microbes into the plate and the impact of other natural and artificial factors that may carry an abundant variety of fungal load in school classrooms (33).

In this study, humidity was negatively associated with the airborne fungal load. The negative association between relative humidity with indoor airborne fungal load was not consistent with what is expected since a positive association between fungal load and relative humidity was already reported $(25,34)$. It requires further investigation to know the reason for the negative association between humidity and indoor air fungal load.

PM10 concentration was significantly associated with fungal load. This is in agreement with a study conducted in the USA (35). However, in another study, particulate matter was not associated with fungal load (33). This might be explained as PM10 distribution is affected by temperature and humidity.

In conclusion, a high fungal load was found in school classrooms in Gondar City compared with sanitary standards of the European Commission for non-industrial premises indoor air biological standards. Age of buildings, area of classrooms, temperature, humidity and concentration of particulate matters in classrooms were associated with indoor fungal load. Aspergillus, Mucor, Penicillium, Candida, Microsporum, Trichophyton, Rhizopus, Alternaria and Fusarium species were the commonly isolated fungi. As a result, proficient corrective methods are needed to combat the problem of indoor air quality in a school indoor environment by

DOI: http://dx.doi.org/10.4314/ejhs.v28i1.2 
controlling the factors contributing to growth of fungi.

\section{ACKNOWLEDGMENTS}

We would like to forward our heartfelt thanks to the Almighty God for giving us the wisdom, knowledge and all the support we needed to do this study. We would like to express our appreciation to the University of Gondar, primary school directors, and teachers. We would also like to thank data collectors, and the University of Gondar, Biology department laboratory technicians.

\section{REFERENCES}

1. Shiaka, G. and S. Yakubu, Comparative analysis of airborne microbial concentrations in the indoor environment of two selected clinical laboratories. IOSR $J$ Pharm BiolSci (IOSR$J P B S), 2013 ; 8: 4$.

2. Dacarro C, Picco AM, Grisoli P, Rodolfi M. Determination of aerial microbiological contamination in scholastic sports environments. $J \quad$ ApplMicrobiol. 2003; 95(5):904-12. https://doi.org/10.1046/j.1365-

2672.2003.02044.xPMID:14633018

3. Gizaw Z, Gebrehiwot M, Yenew C. High bacterial load of indoor air in hospital wards: the case of University of Gondar teaching hospital, Northwest Ethiopia. MultidiscipRespir Med. 2016; 11(1):24. https://doi.org/10.1186/s40248016-0061-4PMID: 27382463

4. Karwowska E. Microbiological Air Contamination in Farming Environment. Pol $\mathrm{J}$ Environ Stud. 2005; 14(4):445-9.

5. World health organization. 2018 [cited 2018 July, 05]; $\quad$ Available fromhttp://www.who.int/news-room/detail/0205-2018-9-out-of-10-people-worldwide-breathepolluted-air-but-more-countries-are-takingaction

6. Haleem Khan AA, Mohan Karuppayil S. Fungal pollution of indoor environments and its management. Saudi J Biol Sci. 2012; 19(4):40526.https://doi.org/10.1016/j.sjbs.2012.06.002PM ID: 23961203

7. Samet JM, Spengler JD. Indoor environments and health: moving into the 21 st century. $A m J$
Public Health. 2003; 93(9):1489-93. https://doi.org/10.2105/AJPH.93.9.1489PMID:1 2948968

8. Sailer MF, van Nieuwenhuijzen EJ, Knol W. Forming of a functional biofilm on wood surfaces. Ecol Eng. 2010; 36(2):163-7. https://doi.org/10.1016/j.ecoleng.2009.02.004.

9. Ayanbimpe GM, Danjuma WS, Okolo MO. Relationship between fungal contamination of indoor air and health problems of some residents in Jos, in Air Quality-Monitoring and Modeling. 2012, InTech: London, SE19SG - United Kingdom.

10. Kalwasińska A, Burkowska A, Wilk I. Microbial air contamination in indoor environment of a university library. Ann Agric Environ Med. 2012; 19(1):25-9. PMID: 22462441

11. Żukiewicz-Sobczak W. The role of fungi in allergic diseases. Volume 30. 2013. pp. 42-5.

12. Shelton BG, Kirkland KH, Flanders WD, Morris GK. Profiles of airborne fungi in buildings and outdoor environments in the United States. Appl Environ Microbiol. 2002; 68(4):1743-53.DOI: 10.1128/AEM.68.4.1743-1753.2002

13. Yassin M, Almouqatea S. Assessment of airborne bacteria and fungi in an indoor and outdoor environment. International Journal of Environmental Science \& Technology. 2010; 7(3):535-44.

14. Andualem Z, Gizaw Z, Bogale L, Dagne H. Indoor bacterial load and its correlation to physical indoor air quality parameters in public primary schools. MultidiscipRespir Med. 2019; 14(1):2. https://doi.org/10.1186/s40248-0180167-yPMID:30680192

15. Airveda. Airveda air quality monitors. 2019 [cited 2019 February, 07]; Available from: https://www.airveda.com/airveda-pm-co2-airquality-monitor

16. Pasquarella C, Pitzurra O, Savino A. The index of microbial air contamination. $J$ Hosp Infect. 2000; 46(4):241-56. https://doi.org/10.1053/jhin.2000.0820PMID: 11170755

17. Sonmez E, Ozdemir HM, Cem EM, Sonmez Y, Salacin S, Ismail OC, et al. Microbiological detection of bacteria and fungi in the autopsy room. Rev Med Leg. 2011; 19(1):33-44. https://doi.org/10.4323/rjlm.2011.33.

DOI: http://dx.doi.org/10.4314/ejhs.v28i1.2 
18. Yang CS, Heinsohn PA. Sampling and analysis of indoor microorganisms. Canada: John Wiley \& Sons; 2007. https://doi.org/10.1002/0470112433.

19. Bartlett KH, Kennedy SM, Brauer M, van Netten C, Dill B. Evaluation and determinants of airborne bacterial concentrations in school classrooms. J Occup Environ Hyg. 2004; 1(10):639-47.

https://doi.org/10.1080/15459620490497744PM ID: 15631055

20. Dumała SM, Dudzińska MR. Microbiological indoor air quality in Polish schools [RocznikOchronaŚrodowiska]. Annual Set The Environment Protection. 2013; 15:231.

21. Rajesh B, Rattan L. Essentials of medical microbiology.Jaypee Brothers Medical Publishers (P) Ltd. 4th ed. New Delhi, 2008. 110002.

22. Sciortino CV Jr. Atlas of clinically important fungi. Canada: John Wiley \& Sons; 2017. https://doi.org/10.1002/9781119069720.

23. CavaleiroRufo J, Madureira J, Paciência I, Pereira C, Teixeira JP, Slezakova K, et al. Indoor air quality in primary schools: preliminary results of the ARIA project 2015.

24. Hussin NH, Sann LM, Shamsudin MN, Hashim $Z$. Characterization of bacteria and fungi bioaerosol in the indoor air of selected primary schools in Malaysia. Indoor Built Environ. 2011; 20(6):607-17. https://doi.org/10.1177/1420326X11414318.

25. Naruka K, Gaur J. Microbial air contamination in a school. Int J CurrMicrobiolAppl Sci. 2012; 2(12):404-10.

26. Heseltine Elisabeth and Rosen Jerome. WHO guidelines for indoor air quality: dampness and mould. WHO Regional Office Europe; 2009.

27. Rao CY, Burge HA, Chang JC. Review of quantitative standards and guidelines for fungi in indoor air. J Air Waste Manag Assoc. 1996; 46(9):899-908.

https://doi.org/10.1080/10473289.1996.1046752 6PMID:8806223

28. Wanner H, Verhoeff A, Colombi A, Flannigan B, Gravesen S, Mouilleseaux A, et al. Indoor Air
Quality and its Impact on Man: Report No. 12: Biological Particles in Indoor Environments. ECSC-EEC-EAEC, Brussels-Luxembourg, 1993.

29. Badri, R.M., R.R. Alani, and S.S. Hassan, Identification and characterization of air bacteria from some school of Baghdad city.Mesop. environ. J, 2016;2(4): p. 9-13.

30. Dananché C, Gustin MP, Cassier P, Loeffert ST, Thibaudon M, Bénet T, et al. Evaluation of hirsttype spore trap to monitor environmental fungal load in hospital. PLoS One. 2017; 12(5):e0177263.

https://doi.org/10.1371/journal.pone.0177263P MID:28486534

31. Ponsoni K, Raddi MS. Indoor Air quality related to occupancy at an air-conditioned public building. Braz Arch Biol Technol. 2010; 53(1):99-103. https://doi.org/10.1590/S151689132010000100013.

32. Adams RI, Bhangar S, Pasut W, Arens EA, Taylor JW, Lindow SE, et al. Chamber bioaerosol study: outdoor air and human occupants as sources of indoor airborne microbes. PLoS One. 2015; 10(5):e0128022. https://doi.org/10.1371/journal.pone.0128022P MID:26024222

33. Viegas C, Faria T, Pacífico C, Dos Santos M, Monteiro A, Lança C, et al. Microbiota and particulate matter assessment in Portuguese optical shops providing contact lens services. Healthcare (Basel). 2017; 5(2):24. https://doi.org/10.3390/healthcare5020024PMID $: 28505144$

34. Huang HL, Lee MK, Shih HW. Assessment of indoor bioaerosols in public spaces by real-time measured airborne particles. Aerosol Air Qual Res. 2017; 17(9):2276-88. https://doi.org/10.4209/aaqr.2017.02.0089.

35. Adhikari A, Reponen T, Grinshpun SA, Martuzevicius D, LeMasters G. Correlation of ambient inhalable bioaerosols with particulate matter and ozone: a two-year study. Environ Pollut. 2006; 140(1):16-28. https://doi.org/10.1016/j.envpol.2005.07.004PM ID: 16183184 